\title{
Results of the Chaulmoogra Treatment in Very Early Cases of Leprosy.
}

\author{
JoSe RodRIGUez.
}

W

HEN in 1925 we started treating individuals with incipient bacteriologically negative lesions, consisting of macules and localised anaesthesia, we expected that such cases, being early, would prove very amenable to the treatment. As a matter of fact, we felt confident that a considerable percentage of them would perhaps be definitely cured by the injections. These expectations were based on the results of our treatment obtained in many early bacteriologically positive cases whose cutaneous lesions cleared up rapidly following a series of injections with the iodised ethyl esters of chaulmoogra oil.

To-day, after a lapse of nine years, during which time most of our cases had been followed up even after apparent disappearance of the macules and the anaesthesia, we are no longer so sure that the chaulmoogra treatment is effective in this very early stage. On the contrary, it is perhaps useless, but as will be seen later in this paper, we are not yet in a position to discard this treatment entirely. We feel that a much larger number of cases than we have studied will have to be observed for a longer period of years before definite conclusions regarding the matter can be arrived at.

It became apparent early in the work that there was need of adopting a more dependable criterion for determining the efficacy of the treatment than by merely noting the changes in the size, number, appearance, nature, etc., of the leprotic lesions. This subject is dealt with in another article, which will be submitted to the Editor of the LERPOSY REviEw, so that it need not be discussed here. Suffice it to say that in our opinion, the best criterion would be to observe the proportion progressing to the bacteriologically positive stage, both in treated and the untreated or trivially treated cases over a period of years. In other words, if a certain treatment were really efficacious, the treated cases should become truly " arrested," i.e., none, or only very few, should become bacteriologically positive as compared with the number becoming positive in the control group.

We have studied two different groups of these early cases, totalling about 500 patients in all.

1. Three hundred and thirty-six children of leprous parents born in the Culion Leprosy Colony previous to 1924, 
followed for five years, during which treatment with iodized ethyl esters was intensively given to some, and none or hardly any to others. It must be stated, however, that the intracutaneous or " plancha" method was not employed in these children. (Phil. Journ. Sci., 1932, Vol. 47, No. 2, pp. 245-258.) In this group, the proportion becoming positive among those receiving adequate treatment was about the same as among those who had received none or only trivial treatment. It was concluded in this study that the drug treatment as a rule was not effective in the " suspicious " or " prodromal," and the early " clinical leper " stages, but that its effects became more manifest when the organisms have appeared in their typical form in the lesions.

2. The second group consists of 225 out-patients of the Cebu Skin Dispensary, studied with Dr. Fidel Plantilla, for periods ranging from seven months to five years. In this group, the results of the special treatment seem to be more favourable, as can be judged from the following table :-

EFFECT OF TREATMENT WITH IODISED WIGHTIANA ETHYL ESTERS IN "CLOSED" CASES OF LEPROSY.

\begin{tabular}{|c|c|c|c|c|c|c|c|c|c|}
\hline \multirow{3}{*}{$\begin{array}{l}\text { Duration } \\
\text { of } \\
\text { Treatment. }\end{array}$} & \multicolumn{9}{|c|}{$\begin{array}{c}\text { REgularity of TREatment. (Percentage of expected number of } \\
\text { injections actually received.) }\end{array}$} \\
\hline & \multicolumn{3}{|c|}{$0-60 \%$} & \multicolumn{3}{|c|}{$61 \%-100 \%$} & \multicolumn{3}{|c|}{ Total. } \\
\hline & Cases & Pos. & $\%$ & Cases & Pos. & $\%$ & Cases & Pos. & $\%$ \\
\hline $0-12 \mathrm{mo}$. & 23 & 3 & 13 & 19 & 0 & 0 & 42 & 3 & $7.1 \pm 3.96$ \\
\hline $13-24$ & 40 & 4 & 10 & 10 & 1 & 10 & 50 & 5 & $10.0 \pm 4.24$ \\
\hline $25-36 \quad$ & 45 & 6 & 13.3 & 9 & 0 & 0 & 54 & 6 & $11.1 \pm 4.27$ \\
\hline $37-48$ & 60 & 14 & 23.3 & 14 & 2 & 14.2 & 74 & 16 & $21.5 \pm 4.78$ \\
\hline Over 48 .. & 5 & 1 & 20 & 0 & 0 & 0 & 5 & 1 & $20.0 \pm 17.97$ \\
\hline Total ... & 173 & 28 & 16.18 & 52 & 3 & 5.77 & 225 & 31 & $13.7 \pm 2.16$ \\
\hline
\end{tabular}

In the above table, patients receiving less than 60 per cent. of their expected number of injections were considered inadequately treated; those receiving more than this amount were considered to have been treated regularly or adequately. It is seen that 16.18 per cent. of 173 receiving irregular treatment had become positive bacteriologically, while only 5.77 per cent. of those receiving adequate treatment became positive. The difference in percentage between the two groups $(10.41 \%+2.88)$ is statistically significant. In this out-patient group, therefore, the 
results are undoubtedly in favour of the properly-treated group.

However, there is no direct correlation between duration of treatment and the percentage becoming positive. Even less became positive of those who have been treated less than one year than of those who have been treated from 35 to 36 months, although the difference is not statistically significant. There are too few of those who have been treated over 48 months to permit even tentative conclusions.

Moreover, we know that most of those who had been able to receive 60 -per cent. or more of their injections, were better off financially than the rest, and could thus afford the transportation expenses necessary to report to the clinic weekly for treatment regularly. Furthermore, they naturally have been under our continual influence and care, while those seldom reporting did not get the benefits of medical advice of general nature. At almost every visit to the dispensary, these patients asked for and were given advice as to food, cleanliness, treatment of skin diseases and intercurrent illnesses, etc. Finally, these were too few cases observed properly so far, only 52 of them having received adequate treatment.

Summarising the results of the treatment in the two above groups of patients with incipient leprosy, totalling about 500 cases, observed for periods ranging from seven months to five years, we regret to have to admit that at the present time our experience is not yet sufficiently extensive to allow definite conclusion on this very important subject. However, we know now that the results have not come up to our original expectations. There is also very little doubt in our minds that if the criterion suggested in this paper were followed, the results with the chaulmoogra preparations are more disappointing in the early bacteriologically negative, neural or macular cases than in those with cutaneous lesions showing acid-fast bacilli.

In our experience the erythematous patches of clinical " tuberculoid" leprosy negative for acid-fast bacilli are as a rule more resistant to both the intramuscular and the intracutaneous injection of the chaulmoogra preparations than the red, acid-fast positive, infiltrated areas typical of the more advanced " cutaneous" stage. If these two types of lesions are followed histologically during a course of intensive treatment, it will be seen that in the case of the "positive" infiltration, there is fairly rapid granulation and fragmentation of the bacilli, disappearance of the globi, thinning out of the proliferated fibrous tissue, and diminu- 
tion of the newly-formed small blood vessels, whereas there is very little change in the cellular structure of treated early macules from month to month.

Therefore, it does not necessarily follow that the earlier the case the better the results, so far as the treatment of leprosy with chaulmoogra oil is concerned.

The above results are certainly unexpected and paradoxical. A few years ago, it would have been impossible to explain these results even theoretically, but we believe that such an explanation is possible now.

The studies of Walker and Sweeney (Journ. Inf. Dis. 1920, Vol. 1, No. 1) and of Schöbl (Phil. Journ. Sci., 1923, Vol. 23, No. 6, pp. 533-541) have shown that chaulmoogra oil and its derivatives inhibit in vitro the growth of acid-fast bacilli in dilutions that have no effect on the growth of nonacid-fast bacteria. These results have been confirmed in our laboratory in Cebu.

Manalang, as a result of his pathologic findings correlated with search for $M$. leprae in these incipient cases (Monthly Bull. of the Phil. Health Serv., 1932, Vol. 12, No. 3, pp. 77-79) believes that " as in $M$. tuberculosis, $M$. leprae has a microscopically invisible ultra virus stage which is responsible for the so-called early lesions pathologically characterised by a perivascular infiltration. ..." In other words, there may exist a cycle in the life history of the organism which develops within the body of the case of leprosy starting from an ultramicroscopic stage, found in the early macules to the solid, acid-fast, staining rods located in the cutaneous infiltrations and nodules.

By using the staining method of Much, my colleagues and I (Phil. Journ. Sci., 1933, Vol. 51, No. 4, pp. 617-629), have been able to demonstrate the presence of Much-positive forms of $M$. leprae in a considerable percentage of leprotic lesions which do not contain acid-fast bacilli. Furthermore, we believe that these non-acid-fast bacilli are not merely degenerated forms because they are found in untreated " closed " or " incipient" cases of leprosy, as well as in previously positive and treated "quiescent" cases. We concluded that Much-positive non-acid-fast forms may represent another stage in the life cycle of the organism.

In the light of the above findings, may it not be possible that the chaulmoogra derivatives act in much the same way in vivo as in vitro (particularly when these drugs are injected intradermally) that is, may they not be more effective in lesions produced by acid-fast forms than in those 
of earlier cases harboring chiefly non-acid phases in the life cycle of the $M$. leprae?

Our own studies lead us to advance the theory that the progress of leprosy in the human body and the effect of the treatment with chaulmoogra oil are probably somewhat as follows :-

In the very early depigmented macule as well as in the early anaesthetic or macule-anaesthetic type of leprosy, $M$. leprae may be present in an as yet undemonstrable form, which causes a distinct reaction in the tissues manifested by round-cell infiltration about the capillaries and arterioles. This unrecognised form has a distinct predilection for the cutaneous sensory nerves. It is possible that the organisms at this stage may be so minute as to be ultra-microscopic, or that no staining method has yet been perfected for their demonstration.

It is presumed that as the organisms gradually increase in size, the character of the tissue response also gradually changes, until by the time the former are demonstrable by the Much's stain, the pathological picture of the lesion will have become the typical "tuberculoid" arrangement. From the nature of the tissue response, characterised by proliferation of endothelial-like cells, it may be presumed that the main defence of the body during this phase lies in the phagocytic activity of these and similar cells of the reticulo-endothelial system.

Later, due perhaps to the evolution of a necessary step in the life cycle of the invading organism, or to some change in the tissues of the host, the bacilli become acid-fast and the phagocytes are no longer able to dispose of them properly. Consequently, the bacilli proliferate within the now powerless phagocytic cells to form the well-known "lepra" cells. Using supravital staining methods, Koike (Jap. Journ. of Dermat. and Urol., 29, 1929) has shown these cells to be real histiocytes, following the classification of Sabin. The acid-fast bacilli may be phagocytosed also by the polymorphonuclear leucocytes of the blood and are thus distributed to other parts of the body.

When the acid-fast bacilli begin to appear, the lesions become thicker, due to accumulation of masses of "lepra cells" and to fibrosis, and also become reddish in colour, due to new formation of minute blood vessels. New lesions appear at the sites of predilection such as the earlobes, etc., due to dissemination of the bacilli by the polymorphonuclear leucocytes. 
At this stage a variable proportion of the bacilli remain non-acid-fast.

It is possible that chaulmoogra oil may exercise an inhibitory effect in vivo against the acid-fast stage of $M$. leprae, as it does in vitro, but not against the non-acid-fast forms. Therefore, the administration of this oil, particularly by the intracutaneous or "plancha " method, where the drug is brought into more or less direct contact with the acid-fast organisms, may bring about their destruction and elimination, together with improvement or disappearance of the infiltrations, nodules, and other manifestations of " activity" of the disease. The patient may then become a " quiescent" or " negative" case, without any manifestations of " activity," and be negative for acid-fasts, but still harbours Gram or Much-positive non-acid-fast bacilli.

When such negatives suffer a " relapse," it simply means that some of the Much-positive non-acid-fast bacilli have become acid-fast again.

It is realised that this hypothesis explaining the development of the leprotic lesions and the variable, paradoxical results of the chaulmoogra treatment, is based on incomplete evidence at the present time. However, this conception may prove useful to those who, like ourselves, have been long baffled by the conflicting and sometimes disheartening results following the use of the chaulmoogra preparations in the different types of this very difficult disease.

\section{Conclusions.}

1. The chaulmoogra preparations are of real value in the treatment of leprosy, but there is still much room for improvement with regard to our knowledge as to their proper indications, limitations, and action in the human body.

2. The chaulmoogra oil derivatives do not seem to be as effective in incipient leprosy as in the more advanced cases with lesions showing acid-fast bacilli. This paradoxical effect may be due to the fact that these drugs are not as a rule as effective against the non-acid-fast stages of the $M$. leprae, which are believed by some workers to be responsible for the earliest manifestations of leprosy, as against acid-fast forms of the organisms which produce the later lesions. 